\title{
Influence of Level of Detail (LOD) in Hydraulic Model Geometry with Demand Allocation by Voronoi Polygon Method on Chosen Parameters ${ }^{\dagger}$
}

\author{
Wojciech Kruszyński * (iD and Artur Zajkowski
}

Faculty of Civil Engineering and Environmental Sciences, Bialystok University of Technology, 15-309 Bialystok, Poland; dziadek.adz@gmail.com

* Correspondence: w.kruszynski@pb.edu.pl; Tel.: +48-693-408-719

† Presented at the Innovations-Sustainability-Modernity-Openness Conference (ISMO'21), Bialystok, Poland, 14 May 2021.

Citation: Kruszyński, W.; Zajkowski, A. Influence of Level of Detail (LOD) in Hydraulic Model Geometry with Demand Allocation by Voronoi Polygon Method on Chosen Parameters. Environ. Sci. Proc. 2021, 9, 35. https://doi.org/10.3390/ environsciproc2021009035

Academic Editors: Dorota Anna Krawczyk, Iwona Skoczko, Antonio Rodero Serrano and Ewa Szatyłowicz

Published: 19 November 2021

Publisher's Note: MDPI stays neutral with regard to jurisdictional claims in published maps and institutional affiliations.

Copyright: (C) 2021 by the authors. Licensee MDPI, Basel, Switzerland. This article is an open access article distributed under the terms and conditions of the Creative Commons Attribution (CC BY) license (https:// creativecommons.org/licenses/by/ $4.0 /)$.

\begin{abstract}
Deciding on the level of model complexity is one of the first decisions that has to be made before engaging in the creation of a functional hydraulic model of a municipal water supply system. There are a number of influencing factors such as time needed to simulate the network, time needed to create such model and ease of use. The aim of this work is to prove that level of detail has influence on parameters such as pressure at measurement points, spread of flow speed and flow volume at different parts of mains. The Voronoi polygon method is one of the basic demand allocation methods, which, in the event of a different number of junctions depending on model complexity, has to generate a varying number of polygons of different sizes used to aggregate the demands.
\end{abstract}

Keywords: modeling; hydraulic; Voronoi; diagram; aggregation; demands

\section{Introduction}

In modern-day Poland, there is an ever growing problem of drinkable water scarcity due to problem of very low water retention. This is caused by many years of neglect concerning water management. The situation began to change due to Poland joining the European Union, which forced the introduction of many changes, including water management, among others. New laws and state organizations have been created to reduce water losses and improve the quality of water supply systems throughout the country. One of such laws is Water Law Act, on the basis of which in the year 2017 the Polish Waters organization was established. The task of this organization is to lead to better water management in the country. Due to new laws and the Polish Water organization, water companies have been obliged to limit water losses. One of most important tools to such an endeavor is the mathematical hydraulic model. Nowadays, such models are implemented in geographical information system. Such an approach allows the creation of a powerful tool by which the user can manage, control and optimize the work of a municipal water system with ease [1].

One of first steps in the creation of a hydraulic model is deciding on model complexity. The level of detail has an influence on a number of factors such as time needed to simulate the network, time needed to create such model and ease of use [2]. The aim of this work was to compare two models with different levels of complexity of the same municipal water supply system. Doing so will enable us to visualize differences in calculated pressure, spread of flow speed and flow volume at different parts of the mains. A very important element of the model work is assigning the water demand recorded at the end consumers to specific nodes of the hydraulic model. One of the popular demand allocation methods is the use of Voronoi polygons method [3,4]. They are created based on nodes of the hydraulic model [5]. Hence, the complexity level used has a measurable impact on the location of 
water demands. This has a direct impact on the simulation results. Higher complexity increases the difficulty level of detecting faults in water supply systems [6].

\section{Methodology}

To conduct the study, two hydraulic models of different levels of detail were created. Their geometry was created in the QGis application, which is open-source geographical information software. Then, the geometry was exported to the simulation software. The existing water supply network of a city in Podlasie Voivodeship was chosen as the basis for the creation of both models. The chosen city was inhabited by around 10,500 people in the first half of 2010. The water network discussed supplies around 10,150 inhabitants. The total length of said network is around $77 \mathrm{~km}$ long.

The total demands in both models, represented in Table 1, for simplicity, were determined on the basis of indicators that took into account the number of inhabitants and type of buildings.

Table 1. Total demands and their types used in both model variants.

\begin{tabular}{ccc}
\hline Type of Demand & Total Demand [CMH] & Number of Demand Points \\
\hline Single-family housing & 1066.00 & 1923 \\
Multi-family housing & 249.98 & 58 \\
Industry & 240.04 & 1 \\
\hline
\end{tabular}

\subsection{Complex Model}

The first model created includes all $77 \mathrm{~km}$ of the network. In total, it consists of 3736 junctions and 3792 pipes. The average pipe length in the model is equal to $20.44 \mathrm{~m}$. The total number of demands allocated through the network is 2192, and on average, each node has 1.1 demands allocated. Voronoi polygons were generated on all 3736 junctions making a mesh that enabled fast and decently accurate allocations of water demands. Figure 1a shows the full range of the hydraulic model with all water supply connections, thus allowing us to almost pinpoint the accuracy of demand allocation shown in green diamonds in Figure 1b.

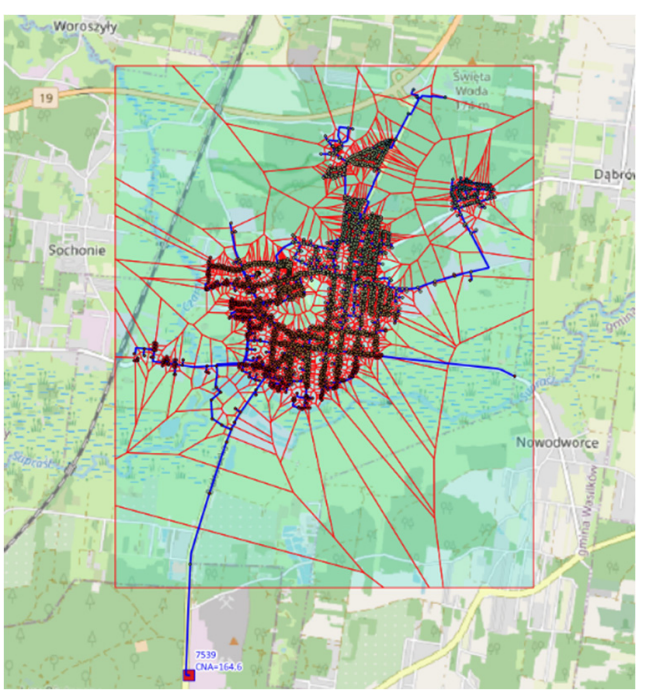

(a)

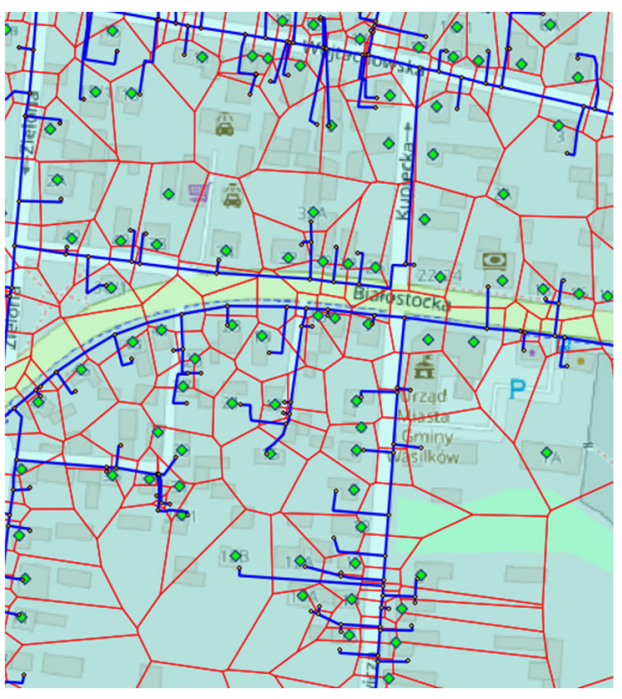

(b)

Figure 1. (a) Full range of hydraulic model with applied Voronoi polygons; (b) section of hydraulic model with applied Voronoi polygons and end recipient location.

\subsection{Simplified Model}

The second model created has a total geometrical length of around $30.2 \mathrm{~km}$. In total, it consists of 100 junctions and 136 pipes. The average pipe length is equal to $222.53 \mathrm{~m}$. 
The average demands allocated to each node are equal to 22.12. Figure 2a shows the full range of the hydraulic model with all water supply connections, thus allowing us to almost pinpoint the accuracy of demand allocation shown in green diamonds in Figure 2b. It is clear from Figure $2 b$ that not every demand was allocated to the correct pipe.

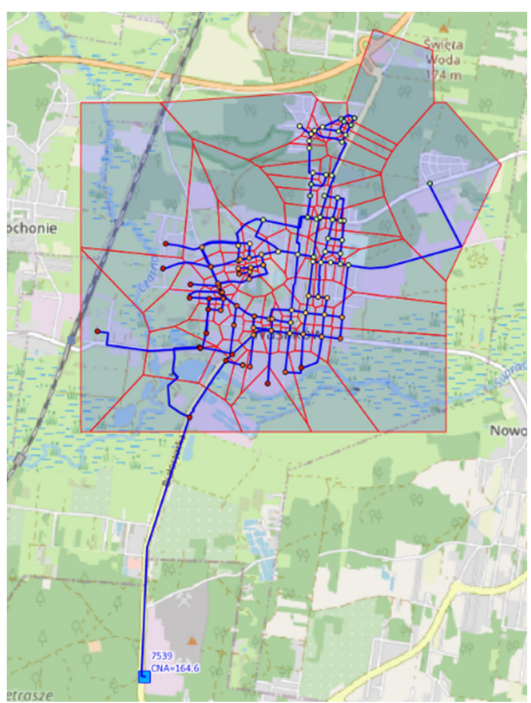

(a)

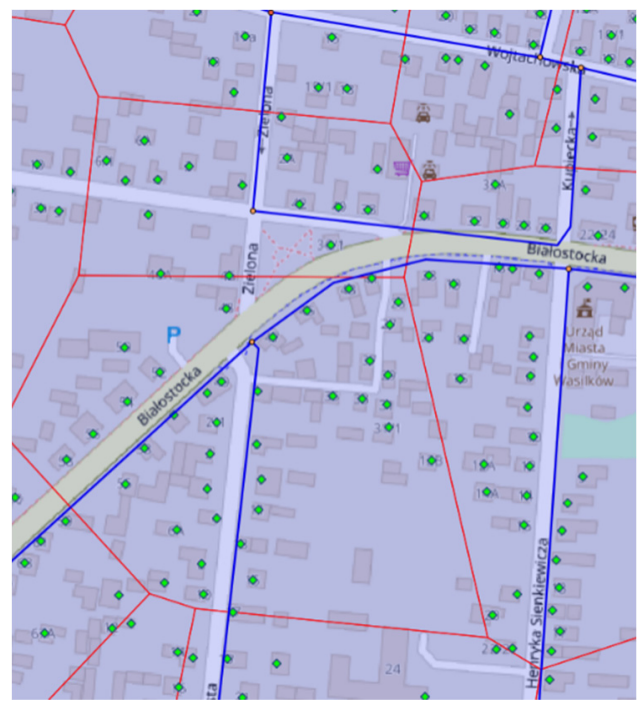

(b)

Figure 2. (a) Full range of hydraulic model with applied Voronoi polygons; (b) section of hydraulic model with applied Voronoi polygons and end recipient location.

\subsection{Comparative Points}

In both models, there are 100 junctions in total that are located at identical coordinates, thus enabling ease of comparison. There were a number of points on the peripheries of the network chosen for pressure comparison. Other than the previously mentioned matter, there were also a number of links chosen for comparison of flow volume and speed.

\section{Conclusions}

Demand allocation in hydraulic modeling can be complex task, but it can be made simple by the use of proper tools. With the use of applications such as QG. the creation of complex Voronoi diagrams is made easy and quick, but the effect on allocation varies depending on the predetermined model complexity. The most important disparity in both of the chosen model sizes is that the complex model offers high fidelity in demand allocation to real water intake point, while the low complexity model offers lesser accuracy of such allocation. Examples can be seen when, for example, Figures $1 b$ and $2 b$ are compared side by side. It can be seen that demands allocated parallel to Białostocka street are allocated to the wrong water main on the less complex model. Differences can also be seen in the other model simulation results such as pressure, where the overall model pressure was lower in the less complex model.

The comparison of flows in both models shows a higher flow resolution in the complex model, which is logical effect of a higher number of nodes dividing the mains and a lower number of demands per node, but the most important difference is that there is a difference in the route that the water takes from the water treatment plant to the final intake point between the two models. This is followed by different flow speeds and volumes.

Author Contributions: W.K. and A.Z. conceived and designed the experiments; A.Z. performed the experiments; W.K. and A.Z. analyzed the data; W.K and A.Z. wrote the paper. All authors have read and agreed to the published version of the manuscript.

Institutional Review Board Statement: Not applicable.

Informed Consent Statement: Not applicable. 
Data Availability Statement: Data is contained within the article.

Acknowledgments: The research was carried out as part of the work WZ/WB-IIŚ/2/19 and financed from the funds for science of the MNiSW.

Conflicts of Interest: The authors declare no conflict of interest.

\section{References}

1. Kruszyński, W.; Dawidowicz, J.C.D. Computer Modeling of Water Supply and Sewerage Networks as a Tool in an Integrated Water and Wastewater Management System in Municipal Enterprises. J. Ecol. Eng. 2020, 21, 261-266. Available online: http://www. jeeng.net/Computer-modeling-of-water-supply-and-sewerage-networks-as-a-tool-in-an-integrated,117533,0,2.html (accessed on 15 March 2021). [CrossRef]

2. Walski, T.M.; Chase, D.V.; Savic, D.A.; Grayman, W.; Beckwith, S.; Koelle, E.B. Advanced Water Distribution Modeling and Management; Haestad Press: San Francisco, CA, USA, 2003; Chapter 10; pp. 417-497.

3. Aurenhammer, F.C.D. Voronoi Diagrams-A Survey of a Fundamental Geometric Data Structure. ACM Comput. Surv. 1991, 23, 345-405. Available online: https://www.cs.jhu.edu/ \{\}misha/Spring16/Aurenhammer91.pdf (accessed on 15 March 2021). [CrossRef]

4. Okabe, A.; Boots, B.; Sugihara, K.; Nok Chiu, S.B. Algorithms for Computing Voronoi Diagrams. In Spatial Tessellations; John Wiley \& Sons, Ltd.: Hoboken, NJ, USA, 2000; Chapter 4; pp. 229-290.

5. Guth, N.; Klingel, P.B. Demand Allocation in Water Distribution Network Modelling-A GIS-Based Approach Using Voronoi Diagrams with Constraints. In Application of Geographic Information Systems; Monwar Alam, B., Ed.; IntechOpen: London, UK, 2012; Chapter 15; pp. 283-302. Available online: https://www.intechopen.com/books/application-of-geographic-informationsystems / demand-allocation-in-water-distribution-network-modelling-a-gis-based-approach-using-voronoi-diagram (accessed on 15 March 2021).

6. Izquierdo, J.; L'opez, P.A.; Mart' 1 nez, F.J.; P'erez, R.C.D. Fault Detection in Water Supply Systems Using Hybrid (Theory and Data-Driven) Modelling. Math. Comput. Model. 2007, 46, 341-350. Available online: https://www.sciencedirect.com/science/ article/pii/S0895717706004006 (accessed on 15 March 2021). [CrossRef] 